\title{
Sonradan Sahiplenilen Golden Retriever Irkı Köpeklerde Ekokardiyografik Bulguların Değerlendirilmesi
}

\author{
Melahat TOKER ${ }^{1, a}$, Mehmet íRIADAM ${ }^{2, b, *}$
}

\author{
${ }^{1}$ Ankara Eğitim ve Araştırma Hastanesi Kardiyoloji Kliniği, Ankara, Türkiye \\ ${ }^{2}$ Harran Üniversitesi, Veteriner Fakültesi, Fizyoloji Anabilim Dalı, Şanlıurfa, Türkiye \\ aORCID: 0000 -0001-5442-4309, bORCID: 0000-0002-9694-6014
}

\begin{abstract}
Geliş Tarihi: 05.05.2020
Kabul Tarihi: 04.11.2020

Özet: Çalışmamız; 2015 ile 2020 yılları arasında Ankara ilinde özel pet kliniklerine getirilen, 6 sahipsiz golden ırkı köpek üzerinde yapıldı. Birçok safkan köpek ırkında olduğu gibi geçici bir hevesle alınan bu hayvanlar ne yazık ki bir süre sonra sokağa bırakılıyorlar. Araştırmamızda sokağa bırakılan 6 adet safkan Golden Retriever ırkı köpeğe, fiziksel muayenelerinin yanı sıra, tam kan, ultrason, röntgen, tansiyon, elektrokardiyografi ve ekokardiyografik tetkikleri uygulandı. Bunun yanı sıra bu hayvanlara aşı takvimine göre aşıları yapıldı. Sokağa bırakılan ve sonradan sahiplenilen bu hayvanların ekokardiyografileri sürekli olarak belirli aralıklarla kontrol edildi. Sonuç olarak; sokağa bırakılan Golden Retriever ırkı sahipsiz köpeklerin, daha sonra sahiplenilip en iyi koşullar da bir yaşam sağlansa bile, bu hayvanlarda sokakta geçirilen yaşamdan kaynaklı birçok kalıcı kalp bozuklukları oluşabilmektedir. Bunlara bağıı olarak da hayvanların başta solunum bozuklukları olmak üzere hem yaşam kalitesi hem de yaşamsal fonksiyonları olumsuz olarak etkilediği belirlenmiştir.
\end{abstract}

Anahtar Kelimeler: Ekokardiyografi, köpek, Ankara, Golden Retriever.

\section{Evaluation of Echocardiographic Findings Later Owned in Golden Retriever Breed Dogs}

Abstract: The study was carried out on 6 derelict Golden Retriever breed dogs brought to private clinics in Ankara province between 2015 and 2020. Unfortunately, these animals, which are taken with temporary enthusiasm, as in many pedigree dog breeds, are left on the street after a while. In the study, 6 pure breed Golden Retriever breed dogs that were left on the streets were subjected to whole blood, ultrasound, x-ray, blood pressure, electrocardiograph and echocardiography examinations in addition to their physical examinations. In addition to these animals were vaccinated on a schedule basis. Echocardiography of these animals that were left on the streets and later owned were continuously followed up at regular intervals. Consequently, even though the Golden Retriever breed of stray dogs left on the streets can be owned and lived in the best conditions, there are many disorders in their hearts permanently caused by a life spent on the streets survived in the best periods of life in the remaining periods. Accordingly, it has been determined that animals negatively affect both quality of life and vital functions, especialy respiratory disorders.

Keywords: Echocardiography, dog, Ankara, Golden Retriever.

\section{Giriş}

Sahipsiz hayvan; insanlar tarafından evcilleştirilmiş ve insanın olduğu her yere insanla birlikte gelmiş, doğada gerek kendi popülasyonuna gerekse insan başta olmak üzere diğer canlı topluluklarına zarar veren kimsesiz canlılar olarak tanımlanmaktadır (Özavcı, 2012).

Maalesef insanlar, bu canlıları kendilerine bağımlı kılmakla kalmayıp, bu hayvanları sokaklara terk etmiş, sonrasında ise bazen sokaklarda bile bu canlıların varlıklarına tahammül edemez olmuşlardır (Atalay ,2004; Demir ve Uğurlu, 2014). Hemen hemen dünyanın her yerinde sahipsiz köpeklerle mücadele edildiği gibi ülkemizde de yer yer bu mücadeleye şahit olmaktayız. Bütün bu mücadelenin yanı sıra hayvan severlerin yetersiz sayıda bulunan barınakların hayvan refahı açısından optimum koşulların sağlanması adına yoğun bir çabaya intiyaç bulunmaktadır. Ama ne acıdır ki, günümüzde köpeklerde olduğu gibi bazen sahipsiz hayvanların hayatta kalma çabaları gerek kendi hayatlarını gerekse insanların hayatlarını riske atacak boyutlara ulaşmıştır. Bunun nedeni; insan popülasyonu içerisinde yaşayan hayvanların sayısındaki artış ile buna bağı olarak gıda kaynaklarının azalmasıdır. Bunun sonucunda da hayvanlar hem kaynaklara ulaşamamakta, açlıktan veya susuzluktan acı çekmekte, hem de halihazırda sınırlı olan kaynaklara ulaşırken insan sağlığını tehdit edebilmektedir (Atalay, 2004: Diez -Prieto ve ark., 2009).

Doğada serbest şekilde yaşayan sahipsiz hayvanların birçoğu yerleşim alanlarının genişletilmesi faaliyetinden olumsuz etkilenmiş su, yemek ve barınma gibi kaynaklara ulaşımları sınırlandırılmıştır (Kılıç ve Sarıerler, 2003). Bu duruma yapıcı bir düzenleme getirilmesi konusunda 
herhangi bir tereddüt yoktur. Sahiplenilen köpekler hem ailelerin sosyo-psikolojisini güçlendirmekte hem de çocuklara sevgi ve paylaşmayı öğretmektedir (Begeç, 2012; Diez-Prieto ve ark., 2009).

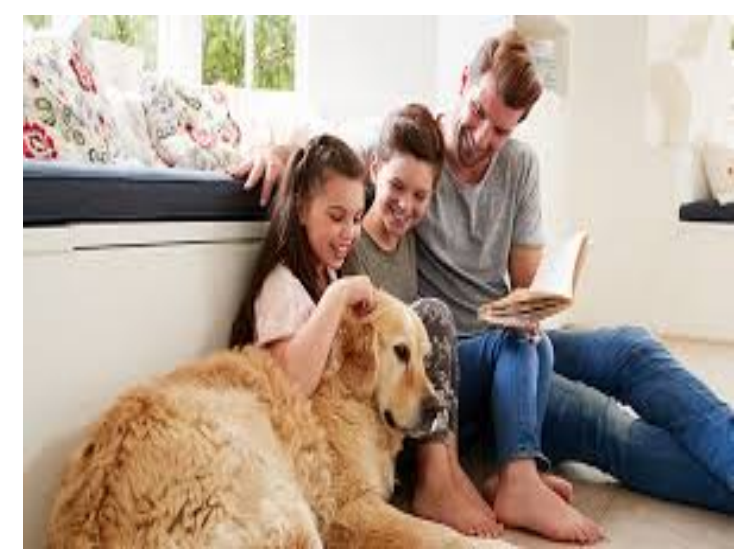

Şekil 1. Hayvan sevgisi çocuğun kişisel gelişimine katkı sağlıyor (Demirsağlık.com.tr)

Çalışmamızda kullandığımız 6 adet Golden Terrier ırkı sahipsiz köpek, bu amaçlarla sahiplendirilen şanslı hayvanlar olup, sosyoekonomik olarak iyi birer ailede hayata devam etmeye başlamışlardır. Köpekler sahiplendikten sonra ilk yapılacak olan işin Veteriner Hekimin kontrolüne almak kaçınılmaz bir gerçektir (Özgür, 2012). Veteriner hekimlerin sahipsiz hayvanlar hakkında sağlıklı bir anamnez alma şansları olmadığından, fiziksel muayenenin yanı sıra, kan tetkikleri, röntgen, ultrason, EKG ve ekokardiyografi yapılarak sağlıklı ya da sağlıksız olduğuna karar verilmektedir. Sahiplenme yapıldıktan sonra köpeklerde kalp hastalıklarının tanısı, klinik, radyografik, elektrokardiyografik ve ekokardiyografik muayene yapılarak konulabilir (Douglas ve Williamson, 2009; Petric ve Tomsic, 2008). Ancak; bazı hastalıklar, radyografik olarak semptom göstermemekle birlikte, görüntünün kalitesi, hekimin bilgi ve becerisi ile teknik faktörlerin sonuçları etkileyebileceği gerçeği de göz ardı edilmemelidir. EKG sadece tamamlayıcı bir muayene yöntemi olup, değerlendirmesi de hastanın genel durumu, kan ve biyokimya değerleri ile göğüs radyografisi ve ekokardiyografi bulgular gibi yardımcı tanısal yöntemlerin sonuçları ile birlikte yapılmalıdır.

Golden Retriever büyük ırk köpek türlerinden birisi olup, sosyal, sıcakkanlı ve akıllı aile köpekleridirler. Uzun, yumuşak ve düz olan iki farklı tüy tabakasına sahip, ikinci tüy tabakası ise su geçirmemektedir. Ayrıca; hayvanların fiziksel özellikleri olarak, burun siyah, kafa biraz bombeli ve geniş, göğüs yapıları güçlü, kuyrukları düz ve uzun, kulakları ise düşük bir yapıya sahiptir. Ayrıca;
Golden Retriever ırk köpeklerde, mast hücre tümörü de dâhil olmak üzere kanser hastalıklarına yatkınlık, kalça displazisi, Von Willebrand adı verilen faktör yetersizliğine bağlı pıhtılaşma bozukluğu, kalp problemleri ve konjenital göz kusurları gibi hastalıkların sıklığı bildirilmektedir (Monnet ve ark., 1995; Ok ve ark., 2010).

Kalp hastalıkları yaşam kalitesini, yaşam süresini ve fonksiyonel kapasiteyi azalttığı için tanı ve sağaltım yönünden önem taşımaktadır. Radyografi; kalp hastalıklarının tanısında kullanılan oldukça yararlı bir yöntemdir. Kalbin büyüklüğü ve şekli hakkında direkt bilgi sağladığı gibi, kalp yetmezliğinin derecesini de ortaya koyabilmektedir (Greco ve ark., 2008). Ayrıca; kalple ilgili olmayan durumları da indirekt olarak kardiyo- pulmoner sirkülasyonu değerlendirmemize olanak sağlamaktadır. Kalp hastalıklarının tanısında ekokardiyografi altın standart bir tanı yöntemi olup. Muayenede; interventriküler septum kalınlığı ve anatomik yapısı, sol ve sağ atrium ventrikül duvar kalınlığı, çapları ve kontraktibilitesi belirlenebilmektedir. Mitral ve trikuspit kapakçıkların anatomik yapısı, kapakçıklar düzeyinden geçen kan akım şiddeti, aortik kapakların anatomik yapısı ve aortik stenozun yanı sıra kalbin çevresinde bulunan perikardial ve plevral SIVI değerlendirilebilir (Chetboul, 2010; Çetin ve ark., 2000). Kalp içinde ve dışında trombüs, kitle, miksoma, apse, kist, yangı gibi intrakardiyak ya da ekstrakardiyak ekojenik artışlar da değerlendirilmektedir. Bunun yanı sıra kalbin anterior, posterior, lateral, septum, inferior gibi ventriküler segmenter duvarlarında hareket bozukluğu ile diastolik disfonksiyonu değerlendirilir (Çeçen, 2003; Schaer, 2003).

\section{Materyal ve Metot}

Çalışmamız, Ocak 2015 ile Mart 2020 tarihleri arasında Ankara'da özel pet kliniklerinde ekokardiyografi yapılan 6 Golden Retriever ırkı köpek üzerinde yürütüldü. Çalışmada; yaşları 5-10 arasında değişen, 3 erkek ve 3 dişi olmak üzere toplam 6 köpek kullanıldı. Golden Retriever ırkı köpekler, renk, boy ve kilo bakımından farklıklar göstermekteydi. Hastalara rutin klinik muayene ve laboratuvar incelemeleriyle birlikte elektrokardiyografi, telekardiyografi, ekokardiyogra-fik tetkikleri uygulandı. Ekokardiyografik görüntüler Toshiba, esaote gibi Renkli Doppler ekokardiyografi cihazları ile alındı ve görüntülerin basımı için Mitsu-bishi siyah -beyaz ya da renkli printer kullanıldı.

Köpeklerin göğüs bölgesi traş edildikten sonra standart ekokardiyografi jeli kullanıldı. Hayvanlar önce sağ yanına yatırılarak sağ parasternal kısa eksen ve uzun eksen pencerelerinden muayene 
edildi. Bu pencerelerde; sol ventrikül'ün M-mod ile 2-D modekokardiogarfik muayenesi yapıldı. Daha sonra prob kalbin basisine doğru yönlendirilerek mitral kapakların ve kranial'e yönlendirilerek pulmoner kapağın 2-D, Pulsed Wave (PW) Doppler ve renkli Doppler muayeneleri yapıldı. Bundan sonra hayvanlar sol yanına yatırılarak sol parasternal uzun eksen görüntüsünde mitral ve triküspit kapakların ekokardiografik muayeneleri yapıldı.

Amerikan ekokardiyografi cemiyetinin belirlediği 17 segmenter duvar hareketi değerlendirilmektedir. İki boyutlu Ekokardiyografi, Continuous-Pulsed Doppler Ekokardiyografi ile yapılan ksifoid kalp penceresinden apikal 3,4 ve 5 boşluk görüntüler alınmaktadır. Şekil 5. Apikal boşluk görüntülerinde kalp boşlukları, sistol ve diyastol çap ölçümleri, mitral, aort ve triküspit kapaklarının yapısı, yetmezliği ve darlığı değerlendirildi.

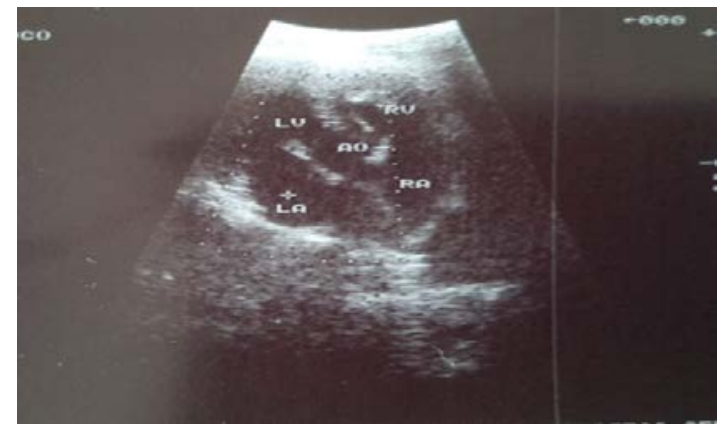

Şekil 2. Köpeklerde apikal 5 boşluk görüntüsü (sol atrium LA, sol ventrikül $L V$, aort $A O$, sağ atrium $R A$, sağ ventrikül $R V$ )

\section{Bulgular}

Hayvanlardan Hachico isimli 3 yaşlı birinci erkek köpeğin ilk muayesinde oldukça bakımsız, korkak ve bitkindi. Bütün muayeneleri yapıldıktan sonra EKG ve Röntgen sonucuna göre yapılan ekokardiyografide taşikardik, kalp boyutlarında sol ventrikül sistolik ve diyastolik boyutlarda artma, atrium ve sol sağ atrium çaplarında artış, kapak yetmezlikleri, ileri derece pericardial ve plevral sIvısı belirlendi. Sahiplenildikten 6 ay sonra biraz toparlamasına rağmen, kontrol ekokardiyografilerinde 6-7 yaşlarında iken, ileri derece kalp krizi geçirdiği (anterior ve inferior duvarlarında hipokinetik alanlar tesbit) edildi. EF ise \%35-40 arasında, mitral ve triküspit kapaklarda ise yetmezlikler belirlendi. Sürekli kontrol altında tutulan hayvanın EF\%50'lere yükseldiği tespit edildi. Bütün bu sonuçlarla hayvan medikal tedavi ile takip edilmektedir.

Kayra isimli ikinci erkek köpekte ise yaklaşık 1 yaş civarında, oldukça bakımsız olup, ilk muayenesinde yapılan bütün tetkikleri ve ekokardiyografisi normaldi. Aradan geçen 5-6 yıl gibi uzun bir zaman sonra birçok patolojiler tespit edildi. Sol ventrikül konsantrik hipertrofisi, posterior duvarda hipokinezi, EF \%48, pulmoner hipertansiyon $40 \mathrm{mmHg}$, mitral yetmezliği ve hafif derece de triküspit yetmezliği belirlendi.

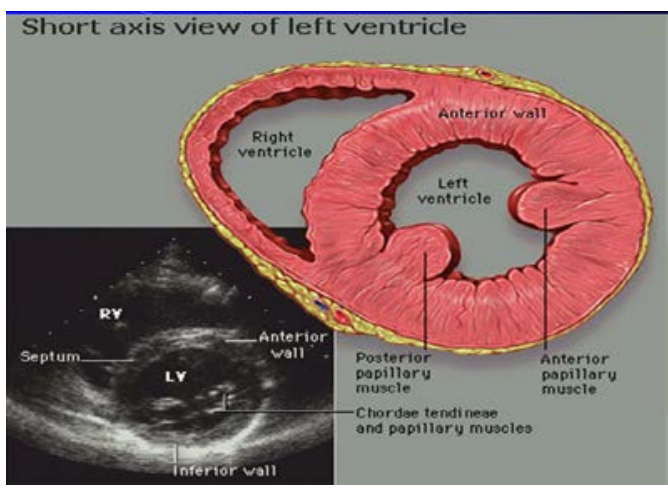

Şekil 3. Kalbin parasternal kısa eksen kesitinde anterior, inferior ve septumun segmenter duvar hareket bozukluğu (T.C. Selçuk Üniversitesi Meram Tıp Fakültesi Radyoloji anabilim dalı anabilim dalı )

Barut isimli üçüncü erkek köpekde; 11 yaşında sokağa terk edilen, zayıf ve kliniklerimizden birisi tarafından sahiplenen hayvandı. Sahiplenildikten sonra yapılan ekokardiyografisinde, sol kalp yetmezliği ve konjenital cortriatrium tespit edildi. Takip edilen ekokardiyografilerinde hayvanda solunum güçlüğü ve yetmezliği belirlenmiş, ileri kalp yetmezliği ile birlikte yoğun perikardial-plevral sıvı artışı belirlendi. Hayvanda halen solunum yetmezliği devam etmektedir.

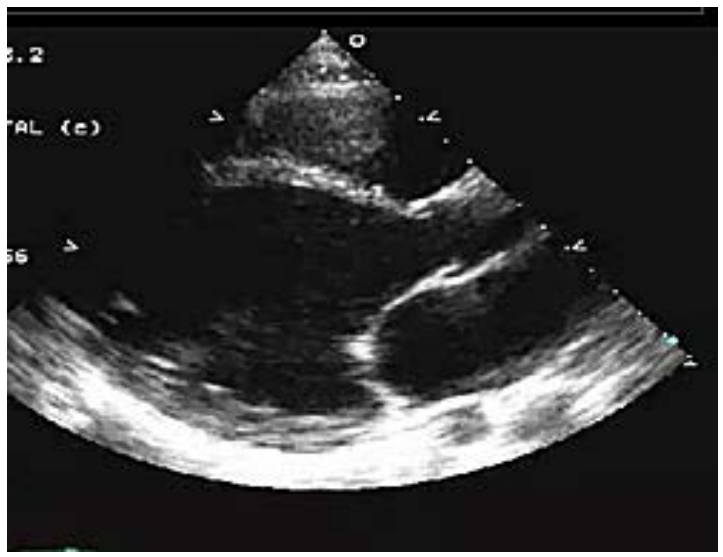

Şekil 4. Köpeğimizde ileri derece sol kalp yetmezliği.

Golden retriever ırkı köpeklerden Gece isimli 1. dişi olan kliniğe ilk getirildiğinde sakin olup, röntgende hafif derecede bir kalp büyümesi belirlendikten sonra yapılan ekokardiyografisinde hafif derecede perikardial sıvı artışı ile birlikte minimal düzeyde mitral kapak yetmezliği tespit edildi. Yıllık periyodik ekokardiyografik muayenelerine devam edilmektedir. 
Dişi köpeklerden 2.si olan Ales'in iki boyutlu (B mode), $M$ mode ve Renkli Doppler ekokardiyografilerin de parasternal uzun ve kısa eksen ile birlikte apikal kesitlerde çalışmaları yapıldı. Doppler ekokardiyografide diastolik disfonksiyonla birlikte mitral kapakta prolapsus tespit edildi. Mitral kapak prolapsusa bağı olarakta yetmezlik akımı izlendi. Ales yıllık yapılan rutin tetkiklerde sağlıklı bir yaşamına devam etmektedir.

Dişi köpeklerden 3. Şila'da sokakta yaşayan, yaklaşık 6 yaşlı olup, sahiplene tarafından ilk kliniğe getirildiğinde rutin kontrollerle birlikte ekokardiyografisi de yapıldı. Kan tetkiklerinde kolesterol ve trigliserinde değişmelerin yanı sıra ekokardiyografi de sadece diyastolik fonksiyon bozukluğu tespit edildi. Diyastolik fonksiyon bozukluğunun nedeni olarak ta kolesterol ya/ya da trigliserit değerlerindeki artışa bağlı olabileceği şeklinde değerlendirildi. Şila'nın yılık periyodik ekokardiyografik muayenelerine devam edilmektedir.

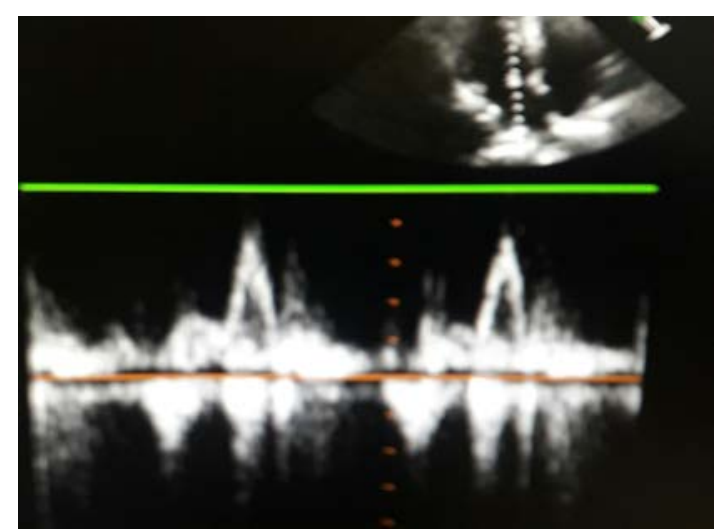

Şekil 5. Köpeklerde iki boyutlu-Renkli Doppler Ekokardiyografiyle diyastolik disfonksionu $(E<A$.)

\section{Tartışma ve Sonuç}

Günümüzde insanlardaki klinik uygulamalarda olduğu gibi hayvanlarda da yaygın olarak kullanılan üç ekokardiografi yöntemi kullanılmaktadır. Bunlar; 2-D (iki boyutlu-real time) ekokardiografi, M-mod ekokardiografi (hareketli-çizgisel) ve Renkli Doppler ekokardiografi teknikleridir. Genel olarak köpeklerde sağ parasternal, sol kaudal (apikal) ve sol kraniyal pozisyonlarda ekokardiyografik görüntüleme yapılmaktadır (Burk ve Ackerman, 1996; Chetboul, 2010). Köpeğin ön ayağının ileriye doğru alması veya yukarıya kaldırılması ve muayene edilen tarafın ters istikametine çevrilmesi, transdüserin hareketini kolaylaştıracak ve de kaburgalar arasındaki boşluğun mesafesi artırılarak kalp penceresinin daha iyi alınması açısından önem arz etmektedir. Köpeklerde yeterli görüntülerin elde edildiği sağ ve sol parasternal (sağ ve sol 3. veya 5 . interkostal aralığının alt $1 / 3$ 'i) ve ksifoid kalp penceresi olmak üzere iki standart bölge tanımlanmaktadır (Bakırel ve Bilal, 1998; Çeçen, 2003). Yaygın olarak kullanılan görüntü şekilleri; solsağ parasternal uzun eksen görüntüde sol-sağ ventrikül sistol ve diyastol çapları, sol atrium, interventriküler septum, posterior duvar kalınlığı, aort kökü-çapı ve çıkan kısımları, ejeksiyon fraksiyon (EF\%) ile franksiyonel kısalma (FS\%) değerlendirilmesi yapılırken, $M$ mode ekokardiyografi bu seviyede kullanılmakta ve çok değerli bilgiler vermektedir. Kısa eksen görüntüleri ile ventriküler giriş ve çıkıs yolları, mitral kapak seviyesinden kapak yapısına ilişkin bilgiler ve sol ventrikül segmenter bozuklukları tesbit edilmektedir (Bonagura ve Ware, 1986; Çeçen, 2003).

Çalışmamızda 6 tane sonradan sahiplenilen Golden Retriever köpeğin fiziksel muayene, bütün rutin kanları, radyolojik muayeneleri, elektrokardiyografi, tansiyon, ateş, B mode -M mode ekokardiografi ve Doppler ekokardiografi muayeneleri yapıldı (Darke ve Else, 1984; Demir ve Uğurlu, 2014). Hayvanların sahiplenildikten birkaç ay gibi kısa bir süre sonra canlandığı, daha cesur ve genel durumlarında iyileşmelerin görülmesine rağmen, maalesef bazı kalıtsal ve edinsel hastalıkları beraberinde taşımaktalardı. Köpeklerde ileri derece kapak yetmezlikleri, kalp krizleri, sistoloik ve diyastolik disfonksiyonları, yüksek tansiyon sonucunda oluşan hipertrofi, kalp çevresinde biriken perikardial ve plevral sıvılar sıvılar yaşamı olumsuz olarak etkilediği bildirilmiştir (Lombard, 1984; Macdonald ve ark., 2009) Çalışmamızda kullandığımız farklı ekokardiografi teknikleri ile incelenen bu hayvanlarda; diyastolik fonksiyon bozukluğunun yanı sıra anterior ve inferior duvarlarda hipokinetik alanlar, minimal ya/ yada maksimal düzeylerde mitral ve/veya triküspit kapaklarda yetmezlikler, sol ventrikül konsantrik hipertrofi, pulmoner hipertansiyon, sol kalp yetmezliği ile birlikte konjenital cortriatrium, hafif yoğun yada şiddetli derecelerde perikardial-plevral sıvılarda artış gibi edinsel ya/ya da kalıtsal fonksiyon bozuklukları belirlendi (Çetin ve ark., 2000; Tidholm ve ark., 1997).

$\mathrm{Bu}$ hayvanlarda kalp ve dolaşım sistemindeki bu bozukluklar başta solunum güçlüğü ve solunum yetmezliği olmak üzere solunumsal bozukluklara, sahipsiz yaşamlarında ki düzensiz ve dengesiz beslenmelerine bağlı olarak ta kolesterol ve trigliserid gibi değerlerdeki artışların kalp ve dolaşım sisteminde olası bozukluklara yol açtığı anlaşılmış ve bu konudaki bildirimlerle uyum göstermektedir (Chetboul, 2010; Rosenthal ve Fox, 1995).

Sonuç olarak; hayvanların sokağa terk edilmesinin köpekler üzerindeki etkilerinin ne kadar 
korkunç olduğunu görmemek imkansızdır. Bütün hayvanlarda olduğu gibi Golden Retriever ırkı köpeklerde de cinsiyet farkı olmaksızın, gençlik dönemlerinin sokakta geçirildiği süre içinde stres, beslenme bozuklukları, kalıtsal ve predispose faktörlerin kalıcı etkileri olduğu görülmektedir. Bu hayvanlar daha sonraki yaşamlarında sahiplenilse ve de yaşam koşulları azami ölçüde iyileştirilse bile geçmişte yaşanılan sıkıntıların telafisi mümkün olamamaktadır. Geçmişte kazanılan ve bir ömür boyu sürecek olan kalp, damar ve solunum sistemine ilişkin bozukluklar her ne kadar tedavi edilirse edilsin tam olarak telafisi mümkün olamamaktadır. Tedavi ve takip edilen bu hayvanlar en iyi koşullarda yaşatılsa bile hiçbir zaman eski sağlıklarına kavuşmaları söz konusu değildir.

Bütün bu sonuçlarla; bütün sahipsiz hayvanlarda olduğu gibi Golden Retriever ırkı köpeklerin hem daha sağlıklı koşullarda yaşatılmasının yanı sıra zenginleştirilmiş kaynaklara erişimlerinin artırılması, hem de kontrolsüz üremelerinin önüne geçilerek insan sağlığının sahipsiz köpeklerin yaşayışından etkilenmemesi amaçlarını da kapsayıcı bir şekilde yapılamasının önemli olduğu düşünülmektedir.

\section{Teşekkür}

Sokakta yaşayan hayvanlara sahip çıkıp ve onları kendi hayatlarına alıp aile bireylerine katan hayvan severlerimize teşekkür etmeyi borç biliyoruz.

\section{Kaynaklar}

Atalay Ö, 2004: Kedi ve Köpeklerin Bazı Davranış Problemleri ve Sağaltım Seçenekleri, Erciyes Univ Vet Fak Derg, 1(2), 147-153.

Bakırel U, Bilal T, 1998: îki köpekte konjestif kardiyomiyopatinin ekokardiyografi ile tanısı. Kafkas Üniv Vet Fak Derg, 4 (1-2), 83- 85.

Begeç S, 2012: Türkiye'de Köpeklerin Savunma ve Koruma Amaçlı Kullanımı. Uludağ Univ Vet Fak Derg, 31 (2), 51-61.

Bonagura JD, Ware WA, 1986: Atrial fibrilation in thedog: Clinical indings in 81 cases. J Am Anim Hosp Assoc; 22, 111.

Burk R.L, Ackerman N, 1996: Small Animal Radiology and Ultrasonography. 2nd edition. Philadelphia: WB Saunders Company, USA.

Chetboul V, 2010: Advanced Techniques in Echocardiography in Small Animals. Vet Clin North Am Small Anim Pract, 40 (4), 529-43.

Çeçen G 2003: Köpeklerde Kardiyak Hastalıkların Tanısında Radyografinin Önemi. Vet Cerrahi Derg, 9 (3-4): 63-70.
Çetin N, Emre B, Toker M, 2000: Perikardiyal Efüzyonlu Bir Köpekte Elektrokardiyografik ve Ekokardiyografik Bulgular. Ankara Üniv Vet Fak Derg, 47, 291-296.

Darke PGG, Else RW, 1984: Canine cardiyomyopati. Vet Annu, 24: 237.

Demir P, Uğurlu K, 2014: Pet Hayvan (Kedi-Köpek) Sahiplerinin Veteriner Kliniklerine Illişkin Beklentileri, istanbul Univ Vet Fak Derg, 40(2), 168-175.

Diez-Prieto I, Garcia-Rodriguez B, Ríos-Granja A, CanoRàbano M, Peńa-Penabad M, Garcia CP, 2009: Cardiac Conotruncal Malformations in a Family of Beagle Dogs. J Small Anim Pract, 50 (11), 597-603.

Dukes M, Cewan J, French A,T, Corcoran B,M, 2002: Doppler Echocardiographyin the Dog: measurement variability and reproducibility. Vet Radiol Ultrasound, 43(2), 144-52.

Douglas SW, Williamson HD, 1970: Veterinary Radiological Interpretation. William Heinmann Medical Books Ltd, London.

Greco A, Meomartıno L, Rajano V, Fatone G, Brunettı A, 2008: Effect of Leftvs Right Recumbency on the Vertebral Heart Score in Normal Dogs. Vet Radiol Ultrasound. 49 (5), 454-455.

Kılıç N, Sarıerler M, 2003: Dog Bite Wounds: A Retrospective Study Cases, YYÜ Vet Fak Derg, 14 (2), 86-88.

Lombard CW, 1984: Echocardiyographic and clinical signs of canine dilated cardiyomyopathy. I Small Anim Pract; 25: 59-70.

Macdonald KA, Cagney O, Magne ML, 2009: Echocardiographic and Clinicopathologic Characterization of Pericardial Effusion in dogs: 107 cases (1985-2006). J AmVet Med Assoc, 235 (12):1456-61.

Ok M, Öztürk AS, Er C, 2010: Üç köpekte konjestif kalp yetmezliği. Eurasian J Vet Sci, 26 (1): 57-62.

O' Grady M, O' Sullivan ML, 2004: Dilate Cardiomyopathy: an Update. Vet Clin Small Anim, 34, 1187-1207.

Özavcı V, 2012: Köpeklerde Capnocytophaga Canimorsus ve Capnocytophaga Cynodegmi Türlerinin Kültür ve Moleküler Yöntemlerle Araştırılması, Doktora Tezi, ADÜ Sağlık Bilimleri Enstitüsü, Aydın.

Özgür A, 2010: Hayvanlarla Yaşamı Paylaşmak, Vet Hek Der Derg, 81 (2), 9-13.

Petric AD, Tomsic K, 2008: Diagnostic Methods of Cardiomyopathy in Dogs -Old and New Perspectives and Methods. Slov Vet Res, 45 (1): 5-14.

Rosenthal SL, Fox PR, 1995: Diastolik Mitral Regurgitation Detectedby PW Doppler Echocardiography and Color Flow Doppler Mapping in 5 Dogs and 2 Cat sith 2nd Degreeand 3rd Degree Atrioventricuar Block. Vet Radiol Ult, 36, 481-485.

Schaer M, 2003: Clinical medicine of the dog and cat. (3rd edition), Manson Publishing, Phladelfia, USA.

*Yazışma Adresi: Mehmet IRIADAM

Harran Üniversitesi Veteriner Fakültesi Fizyoloji Anabilim Dalı Eyyübiye Yerleşkesi, Şanlıurfa-Türkiye

e-mail: miriadam@harran.edu.tr 